\title{
Investigation of Seasonal Variations of Dynamic Characteristics of a Concrete Bridge by Employing a Wireless Acceleration Sensor Network System
}

\author{
Youqi Zhang, Yasunori Miyamori, ${ }^{*}$ Takanori Kadota, ${ }^{1}$ and Takehiko Saito \\ Kitami Institute of Technology, 165 Koen-cho, Kitami, Hokkaido 090-8507, Japan \\ ${ }^{1}$ Oriental Consultants Co. Ltd., 3-12-1 Honmachi, Shibuya-ku, Tokyo 151-0071, Japan
}

(Received June 20, 2016; accepted November 28, 2016)

Keywords: wireless acceleration sensor, structural health monitoring, seasonal effects, dynamic characteristics, multispan prestressed concrete railway bridge

In this study, a fundamental application of a wireless acceleration sensor network system was carried out by conducting two bridge vibration experiments in autumn and winter. Seasonal effects on the dynamic characteristics of a multispan ballasted prestressed concrete railway bridge were investigated by employing a wireless acceleration sensor network system as a basic study of structural health monitoring technology. The dynamic parameters of every single span, such as natural frequencies, damping ratios, and mode shapes, were determined from free damped vibration, which was caused by human jumping excitation. Owning to the excitation pattern limitation, three modes were obtained in the experiments. A three-dimensional (3D) finite element (FE) model was made to show the rationality of the experimental result. Comparison of the autumn and winter experimental results showed that the natural frequencies of the bridge were significantly higher in winter than in autumn. The frozen ballast and frost on the deck and walkway were revealed to be reasonable explanations for this phenomenon. Meanwhile, the variations of damping ratios were not as simple as those of the natural frequencies. No variation regularity of damping ratios was obvious.

\section{Introduction}

With the continuous development of structural health monitoring (SHM) technology, the wireless acceleration sensor network has made civil structure vibration measurements more flexible and efficient. The high cost, high labor requirement, and time consumption associated with the installation of wired sensors can be greatly reduced by employing wireless acceleration sensors. In previous studies, the wireless acceleration sensor network system was applied in many actual bridges. ${ }^{(1-3)}$ Meanwhile, applying wireless acceleration sensor networks in the civil SHM field is becoming inevitable in the future.

For SHM, it has been widely accepted that the vibration-based method provides the possibility of detecting and locating structural damage. ${ }^{(4)}$ The shifts of dynamic parameters such as natural frequencies, damping ratios, mode shapes, and other relevant numerical parameters may indicate damage information. ${ }^{(2,5,6)}$ However, dynamic parameters are easily effected by environmental

"Corresponding author: e-mail: miyamoya@mail.kitami-it.ac.jp http://dx.doi.org/10.18494/SAM.2017.1421 
factors such as temperature and frost. ${ }^{(7,8)}$ To comprehend the effect of the environment on dynamic characteristics, the analysis of the variations of dynamic parameters in different seasons was carried out employing a wireless acceleration sensor network system. It has the potential to provide reasonable explanations of the seasonal variations of bridge dynamic parameters.

In this study, a fundamental application of a wireless acceleration sensor network system was carried out by conducting vibration experiments on a multispan ballasted railway bridge in autumn and winter. Seasonal effects on dynamic characteristics were investigated as a basic study of SHM technology. Tests were conducted on every single span. Meanwhile, a single-span threedimensional (3D) finite element (FE) model was established by Midas Civil 2015. Experimental frequencies and mode shapes were compared with analytical results to show the rationality of the experimental results. Finally, discussion on the seasonal variations of dynamic parameters was carried out.

\section{Experiment Instrumentation and the Bridge}

\subsection{Wireless acceleration sensor network system}

The wireless acceleration sensor network system was used as the main measurement instrumentation in this study. The network system consists of three parts: wireless acceleration sensors, a central Imote2 gateway node, and a laptop computer.

\subsubsection{Wireless acceleration sensor}

A typical original wireless acceleration sensor is shown in Fig. 1. ${ }^{(9)}$ It performed as a leaf node during the measurement and was controlled by the BEHELMO software in the laptop computer. It was composed of 3 electronic circuit boards. From top to bottom, the electronic circuit boards are the SHM-A or SHM-H acceleration sensor board, ${ }^{(10)}$ Imote2 high-performance wireless sensor network node board, ${ }^{(1)}$ and battery board.

The SHM-H acceleration sensor board was applied in this study. It was developed at the University of Illinois and has the capacity of 3 -axis measurement. For the $x$ - and $y$-axes, the measurement range is $-2-2 \mathrm{G}$ and the least significant bit (LSB) is about 0.14 gal. On the other

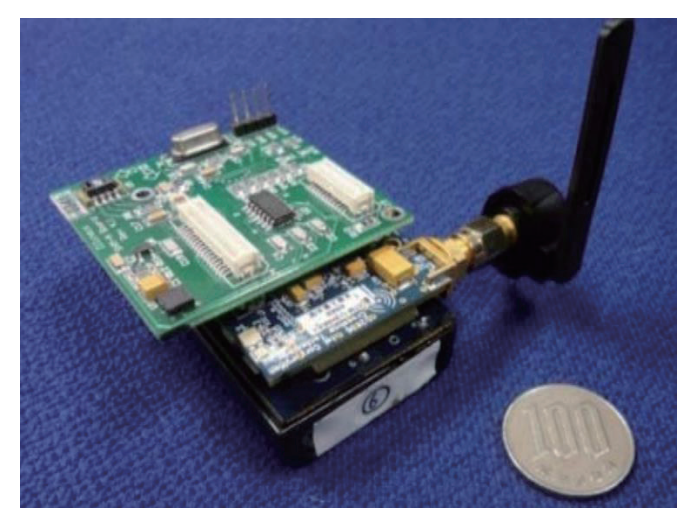

Fig. 1. (Color online) Original wireless acceleration sensor. 
hand, the $z$-axis was designed with a highly sensitive accelerometer. The LSB of the $z$-axis is 0.014 gal, which is 10 times more accurate than those of the $x$ - and $y$-axes. As a result, the measurement range of the $z$-axis is much smaller than those of the $x$-and $y$-axes. The measurement range of the $z$-axis is switchable between $-0.2-0.2 \mathrm{G}$ and $0.8-1.2 \mathrm{G}$. This switch function makes the acceleration measurement more flexible.

The Imote2 high-performance wireless sensor network node board from Crossbow was designed to achieve intelligent communication between nodes and acquire and process data. During measurement, data is stored in the memory flash of Imote2. Then, the stored data is sent to the laptop computer via the central Imote 2 gateway node. The Imote 2 board supports a $250 \mathrm{~kb} / \mathrm{s}$ data rate with 16 channels in the $2.4 \mathrm{GHz}$ band.

Owing to the low capacitance of the original power supply system, a new constant power supply system was developed at Kitami Institute of Technology, as shown in Fig. 2. The new constant power supply system was powered by six AA rechargeable Ni-metal hydride ( $\mathrm{MH})$ cells, and the supplied voltage was fixed at $4.5 \mathrm{~V}$. In addition, the constant power supply system also allowed the wireless acceleration sensor to be waterproof. This makes it possible to apply the wireless acceleration sensor in rainy or snowy weather.

\subsubsection{Wireless Imote2 gateway node}

The wireless Imote2 gateway node was connected to the laptop computer. The two main functions of the gateway node are to launch instructions to the leaf node sensors and collecting data from the leaf node sensors, all by wireless communication.

\subsection{Temperature sensor}

In this research, one EL-USB-2 temperature sensor was used as a thermometric instrument to record the air temperature on the experiment days, as shown in Fig. 3. The measurement range of EL-USB-2 is $-35-80{ }^{\circ} \mathrm{C}$, and the resolution is $0.5^{\circ} \mathrm{C}$. EL-USB- 2 can be easily set up, and the sampling frequency is $1 / 5 \mathrm{~Hz}$.

\subsection{Information on the bridge}

Mukagawa Bridge is a five-span ballasted prestressed concrete (PC) railway bridge located in Kitami City, Hokkaido, Japan. The construction was completed in 1977. The length of each span is $32.02 \mathrm{~m}$ and the width is $5.5 \mathrm{~m}$. A general view of the bridge is shown in Fig. 4 and a

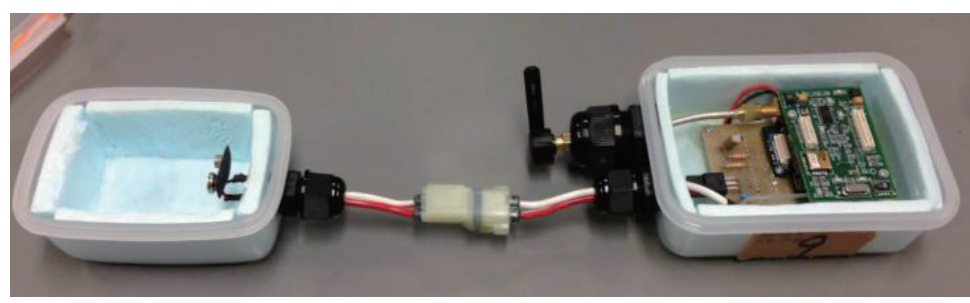

Fig. 2. (Color online) Power supply system upgraded wireless acceleration sensor. 


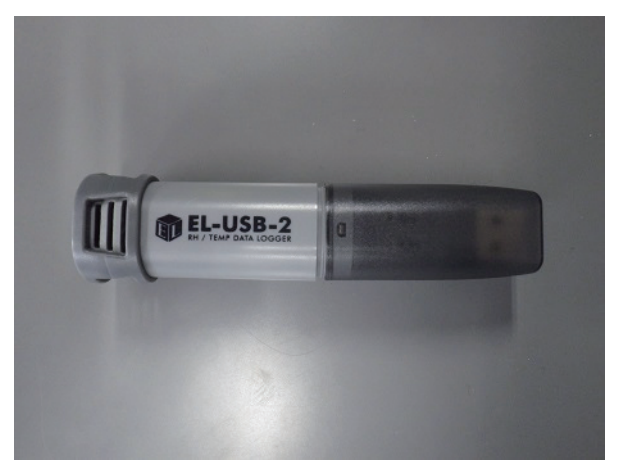

Fig. 3. EL-USB-2 air temperature sensor.

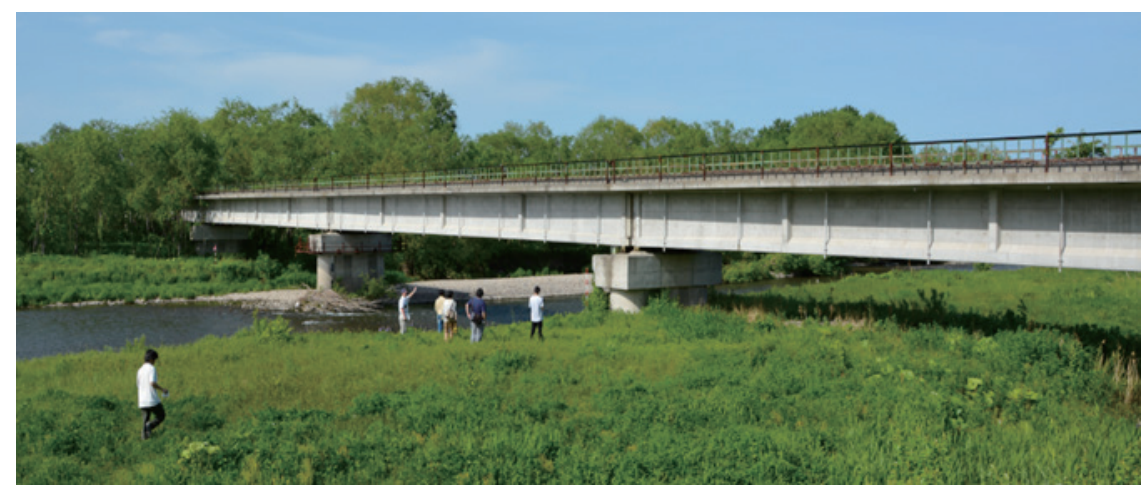

Fig. 4. (Color online) General view of Mukagawa Bridge.

general drawing is shown in Fig. 5. The bridge is along the railway line between Kitami City and Ikeda Town. In order to distinguish the different elements of the bridge, the spans from the Ikeda direction to the Kitami direction were named Spans 1 to 5, and the piers from the Ikeda direction to the Kitami direction were named Piers 1 to 4 . All the spans have the same design and every span is composed of three I-shaped PC girders, as shown in Fig. 6. The girders are simply supported at every end by metallic line bearing supports, as shown in Fig. 7. The heights of the four concrete piers differ. Pier 4 is much shorter than the other piers. As the bridge has been out of service for several years, tracks and sleepers had already been removed.

\section{Vibration Experiment}

In this study, the experiments were conducted in autumn and winter to investigate how environmental variations affect the dynamic characteristics of the bridge. In comparison with dynamic parameters of the bridge in autumn, the bridge dynamic parameters in winter have more influencing factors, such as low temperature, frost, and snow load. The autumn experiment was conducted in November and the winter experiment was conducted in February. Furthermore, in every experiment, tests were conducted on every single span to investigate its dynamic characteristics, and all acceleration sensors were fixed in one span in a test. 


\begin{tabular}{|c|c|c|c|c|c|c|c|}
\hline \multirow{3}{*}{ Ikeda } & \multicolumn{6}{|c|}{158.80} & \multirow[b]{2}{*}{ Kitami } \\
\hline & 32.02 & 32.02 & 32.02 & 32.02 & & 32.02 & \\
\hline & Span 1 & Span 2 & Span 3 & Span 4 & $\sqrt{6}$ & Span 5 & \\
\hline & & & & & Pier 4 & & t 2 \\
\hline
\end{tabular}

Fig. 5. General drawing of Mukagawa Bridge.

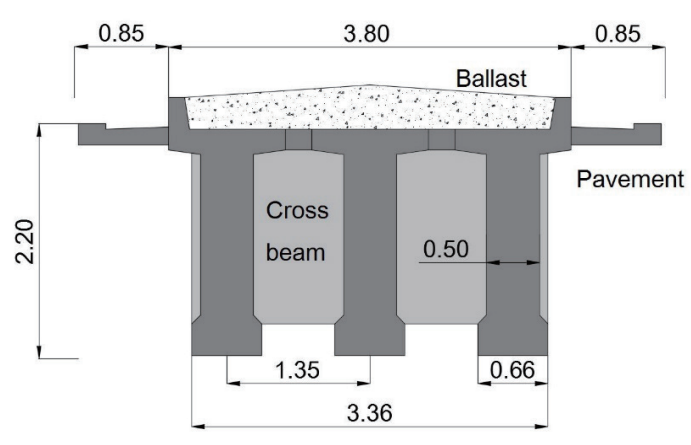

Fig. 6. Sectional view of the bridge.

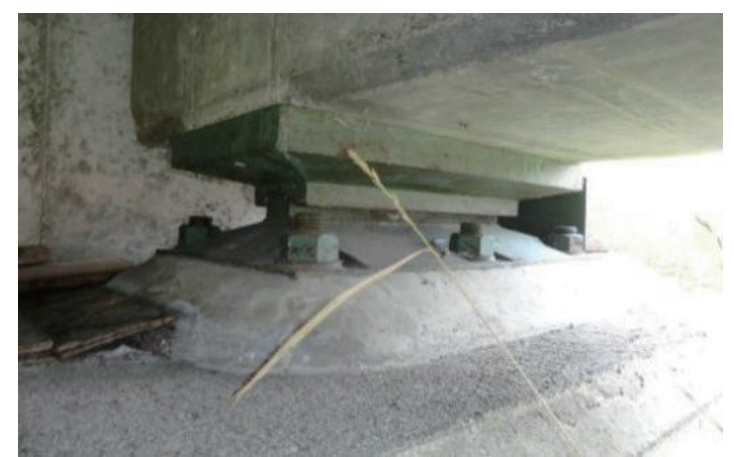

Fig. 7. (Color online) Line bearing support.

The dynamic parameters were identified using a damped free vibration waveform generated by human jumping excitation. The measurement setting of the acceleration sensors was a $280 \mathrm{~Hz}$ sampling frequency with a $30 \mathrm{~s}$ sampling period.

Data processing was carried out by the following steps. Firstly, the power spectrum of every acceleration data channel was obtained by fast Fourier transform. Secondly, natural frequencies were identified by the peak picking method. Thirdly, damping ratios were calculated by the halfpower bandwidth method. Finally, mode shapes were estimated by the cross-spectrum method.

\subsection{Experimental procedure}

The wireless acceleration sensor distribution map in the autumn vibration experiment is shown in Fig. 8. There were five tests in total. Every test was concentrated on only one span. All tests were conducted one by one and the acceleration data was collected via the gateway node to the laptop computer.

In the winter experiment, the acceleration sensor distribution patterns were adjusted slightly, as shown in Fig. 9. The existence of deep snow on the deck during the winter experiment increased the difficulty in installing acceleration sensors, as shown in Fig. 10. Therefore, the number of acceleration sensors was reduced. Owing to the deep snow, the distribution mass on the bridge deck increased significantly. The increase in the distribution mass led to the decrease in the natural frequencies. Hence, in order to estimate the effect of snow load, $0.5 \times 0.5 \mathrm{~m}^{2}$ snow sampling on every span was carried out, and the snow depths are shown in Table 1. After measuring the mass of the snow samples, the snow density was obtained, and then the snow mass of every span could be estimated by easy calculation, also shown in Table 1. The original structural mass of one span is $336 \mathrm{t}$, which was calculated using the FE model, and the ballast mass $(61 \mathrm{t})$ was obtained from the design 


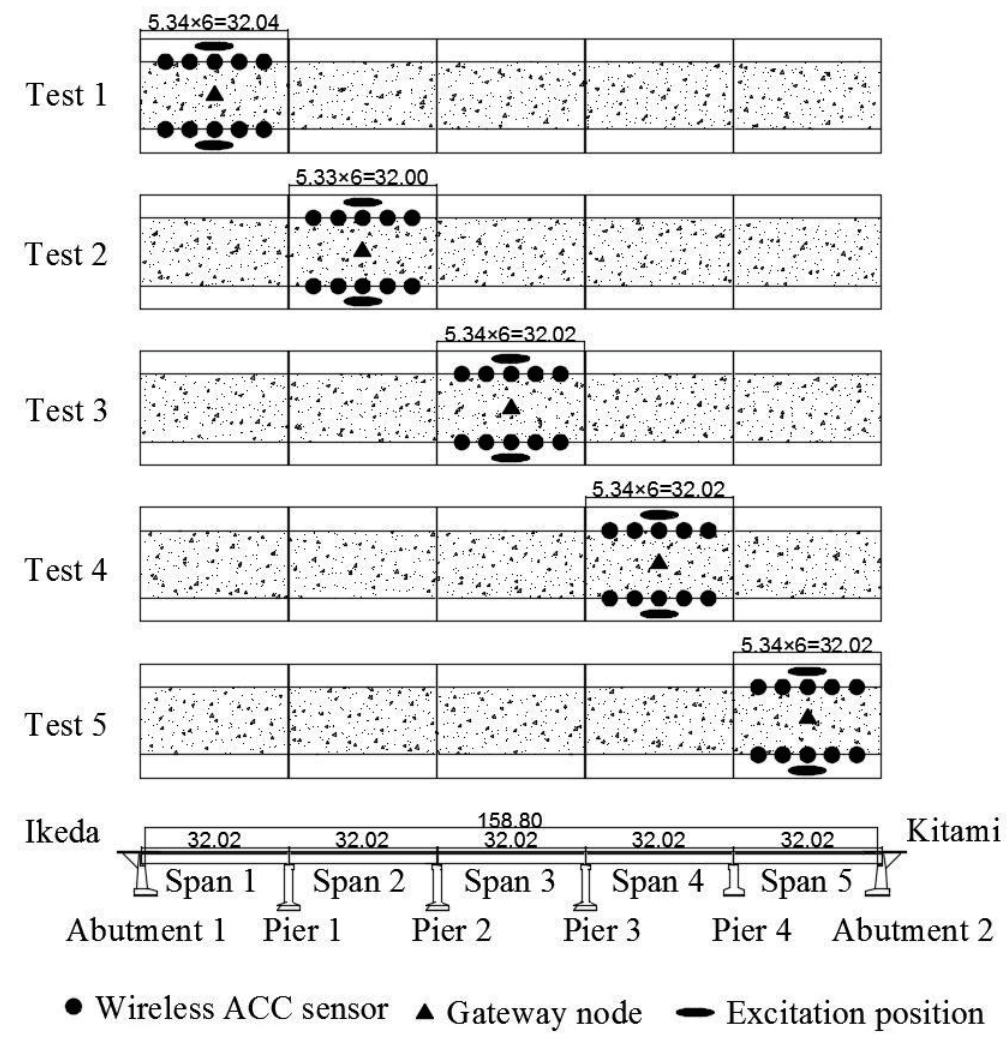

Fig. 8. Autumn experiment acceleration sensor distribution patterns.

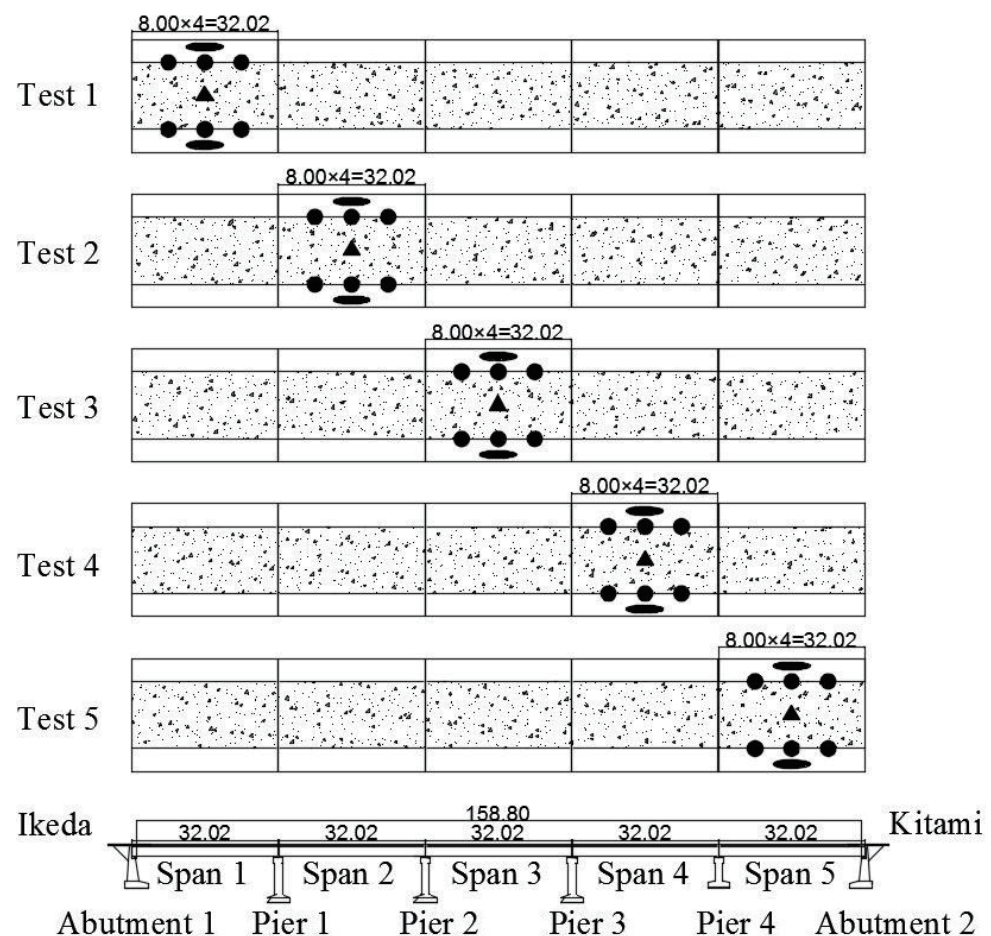

- Wireless acceleration sensor $\Delta$ Gateway node - Excitation position

Fig. 9. Winter experiment acceleration sensor distribution patterns. 


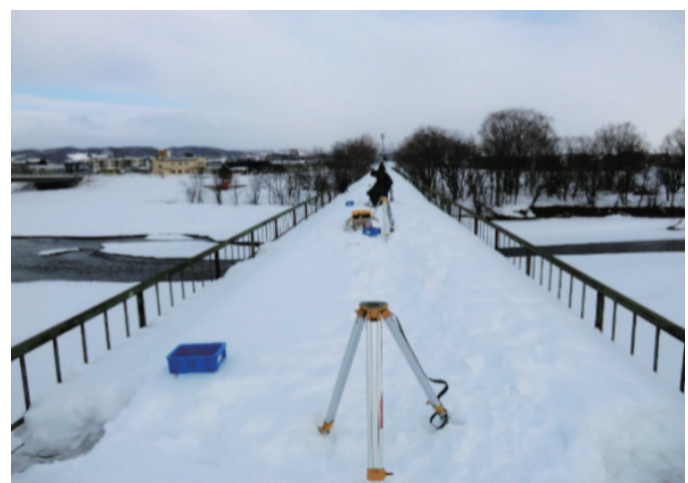

(a)

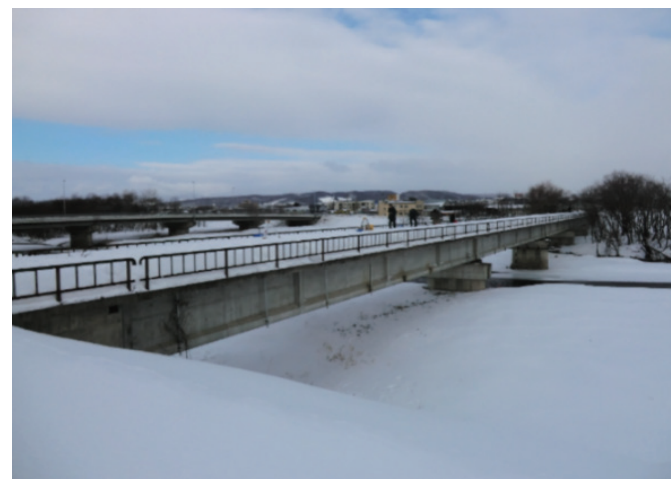

(b)

Fig. 10. (Color online) General view of Mukagawa Bridge in winter. (a) Front view and (b) side view of the bridge.

Table 1

Snow depth and mass.

\begin{tabular}{lcccccc}
\hline Location & Span 1 & Span 2 & Span 3 & Span 4 & Span 5 & Average \\
\hline Depth $(\mathrm{cm})$ & 42 & 50 & 57 & 58 & 33 & 48 \\
Snow mass $(\mathrm{t})$ & 23.74 & 20.29 & 22.17 & 21.21 & 22 & 21.88 \\
\hline
\end{tabular}

manual. Therefore, the existence of snow load resulted in a 5.23\% mass increase for every span, which could be one factor leading to the decrease in the natural frequencies.

\subsection{Vibration experiment result}

The three lowest eigenmodes were identified from the experiments. As the vertical excitation position was in the middle of every span, only the vertical bending mode, lower torsional mode, and higher torsional mode could be accurately identified. No other modes were identified because they were not effectively excited. Three identified eigenmode parameters are sufficient to study the phenomenon and mechanism of the seasonal variations of dynamic characteristics.

The autumn experiment results are shown in Table 2, whereas the winter experiment results are shown in Table 3. As an example of identified mode shapes, the mode shapes of Span 4 in both experiments are listed in Table 4. Eigenmodes could be summarized as follows. The first mode was the vertical symmetric bending mode. The second mode was the lower torsional mode. The third mode was the higher torsional mode. As shown in every column in Table 2 or 3 , the natural frequencies of the same mode of different spans in the same experiment were different. This phenomenon could be reasonably explained by the different heights of the abutment or pier. In both autumn and winter experiments, human jumping was the only excitation method. In this case, the excitation energy is insufficient to produce the bearing displacement of the line bearing supports. Therefore, the girders and the adjacent abutment or pier could be seen as a frame structure. The higher the abutment or pier, the lower the structural stiffness of the frame structure. Because of the low structural stiffness, natural frequencies of Spans 2 and 3 are slightly lower than those of the other spans. 
Table 2

Autumn experiment results.

\begin{tabular}{lcccccc}
\hline \multirow{2}{*}{ Location } & \multicolumn{2}{c}{ Mode 1 } & \multicolumn{2}{c}{ Mode 2 } & \multicolumn{2}{c}{ Mode 3 } \\
& Frequency $(\mathrm{Hz})$ & Damping ratio & Frequency $(\mathrm{Hz})$ & Damping ratio & Frequency $(\mathrm{Hz})$ & Damping ratio \\
\hline Span 1 & 4.2 & 0.0073 & 7.6 & 0.0112 & 21.33 & 0.0076 \\
Span 2 & 3.9 & 0.0124 & 7.2 & 0.0088 & 21.3 & 0.0064 \\
Span 3 & 4.0 & 0.0095 & 6.8 & 0.0101 & 21.33 & 0.0099 \\
Span 4 & 4.3 & 0.0062 & 8.4 & 0.0067 & 22.0 & 0.0057 \\
Span 5 & 4.2 & 0.0071 & 8.4 & 0.0073 & 22.0 & 0.0051 \\
\hline
\end{tabular}

Table 3

Winter experiment results.

\begin{tabular}{lcccccc}
\hline \multirow{2}{*}{ Location } & \multicolumn{2}{c}{ Mode 1 } & \multicolumn{2}{c}{ Mode 2 } & \multicolumn{2}{c}{ Mode 3 } \\
& Frequency $(\mathrm{Hz})$ & Damping ratio & Frequency $(\mathrm{Hz})$ & Damping ratio & Frequency (Hz) & Damping ratio \\
\hline Span 1 & 4.9 & 0.0068 & 8.7 & 0.0158 & 23.8 & 0.0097 \\
Span 2 & 4.4 & 0.0055 & 7.8 & 0.0076 & 23.7 & 0.0092 \\
Span 3 & 4.4 & 0.0072 & 7.3 & 0.0100 & 23.7 & 0.0063 \\
Span 4 & 4.8 & 0.0095 & 9.3 & 0.0131 & 24.0 & 0.0142 \\
Span 5 & 5.0 & 0.0102 & 9.2 & 0.0127 & 24.7 & 0.0104 \\
\hline
\end{tabular}

Table 4

(Color online) Mode shapes of Span 4.

Mode 1 Mode 2

\subsection{FE model analysis}

In order to verify the rationality of the experimental natural frequencies and mode shapes, a 3D single-span FE model was established in strict agreement with the design blueprints and field inspection. Both girders and cross-beams were modeled with six-degrees-of-freedom beam elements. The stiffness and mass of the ballasts were considered by increasing the stiffness and density of concrete. For boundary conditions, the applied roller supports were used to model the line bearing supports. The average natural frequencies of all spans of every mode and the mode shapes of Span 4 in the autumn experiment were compared with the analytical results to show the 
rationality of the experimental results, as shown in Table 5. The experimental natural frequencies and mode shapes agree well with the analytical results, and the maximum error rate of the natural frequency is $6.5 \%$. To sum up, the results of the autumn experiment are reasonable and acceptable.

\section{Analysis and Discussion}

Three eigenmodes were studied to comprehend the seasonal effect on the dynamic characteristics. Natural frequencies and damping ratios are summarized in Figs. 11-13 separately by mode. In every figure, the dynamic parameters of five spans in both autumn and winter experiments are clearly presented. The dynamic parameters are shown as dots, and the dots of every two adjacent spans are connected by a line to show the mode frequency variation trend. It is possible to give a relative presentation of the different local dynamic behaviors of the bridge.

\subsection{Discussion of natural frequencies}

A detailed comparison of the natural frequencies, which were identified in autumn and winter experiments, is shown in Figs. 11(a)-13(a). The natural frequencies increased in winter on every span for every mode, and the differences in the natural frequencies between winter and autumn

Table 5

(Color online) Comparison of dynamic parameters between experimental and analytical results.

\begin{tabular}{|c|c|c|c|c|}
\hline \multicolumn{2}{|c|}{ Dynamic parameters } & Autumn experiment & \multirow[t]{2}{*}{ FE model analysis } & \multirow[t]{2}{*}{$\begin{array}{l}\text { Frequency } \\
\text { difference }\end{array}$} \\
\hline Mode 1 & Mode shape & & & \\
\hline & Frequency $(\mathrm{Hz})$ & 4.11 & 4.27 & $3.89 \%$ \\
\hline \multirow[t]{2}{*}{ Mode 2} & Mode shape & & & - \\
\hline & Frequency $(\mathrm{Hz})$ & 7.69 & 7.30 & $5.12 \%$ \\
\hline
\end{tabular}

Mode 3 Mode shape
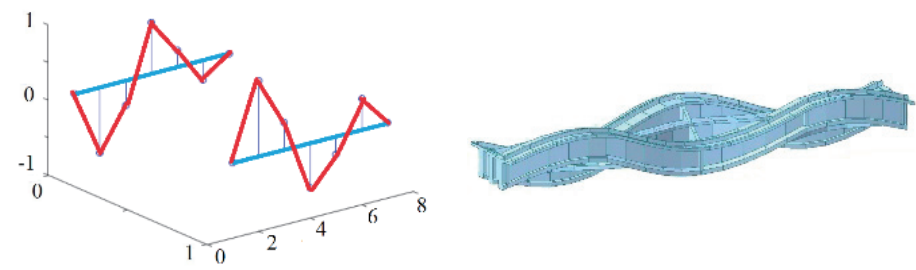


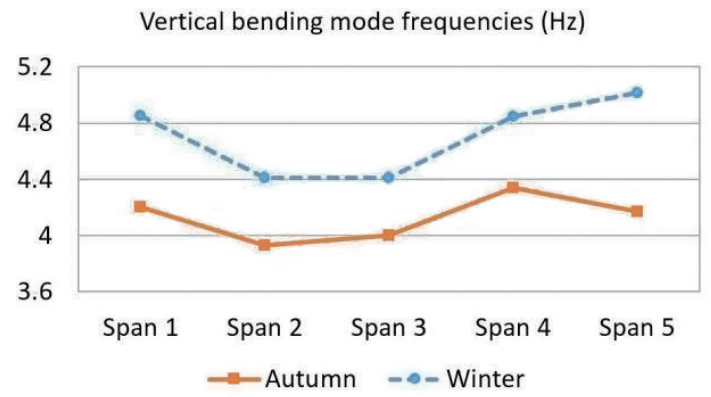

(a)

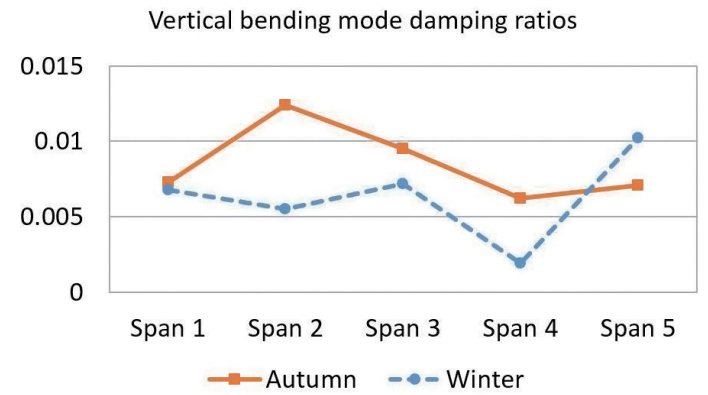

(b)

Fig. 11. (Color online) First-mode parameters of five spans in autumn and winter. (a) Frequency and (b) damping ratio.

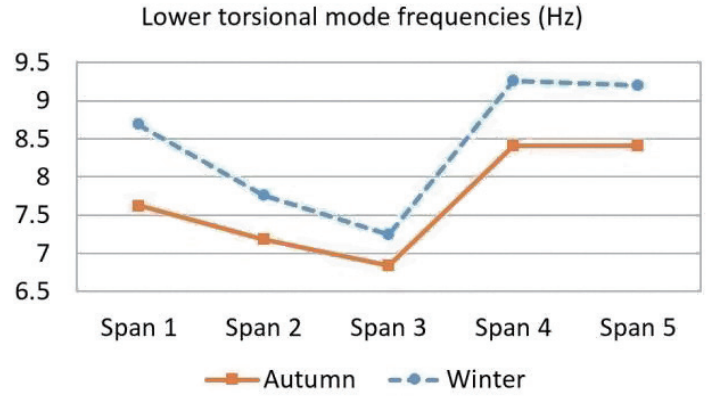

(a)

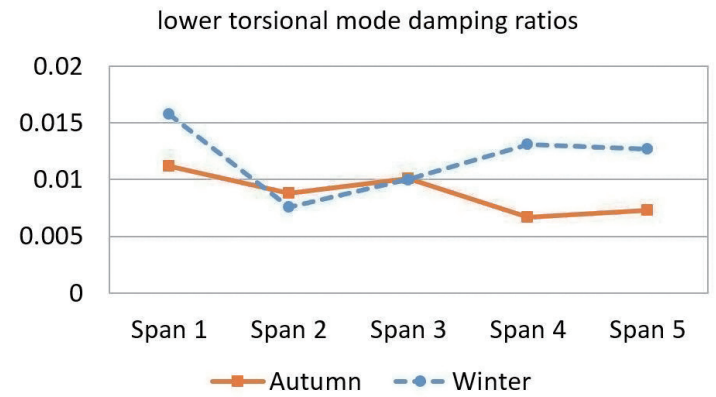

(b)

Fig. 12. (Color online) Second-mode parameters of five spans in autumn and winter. (a) Frequency and (b) damping ratio.

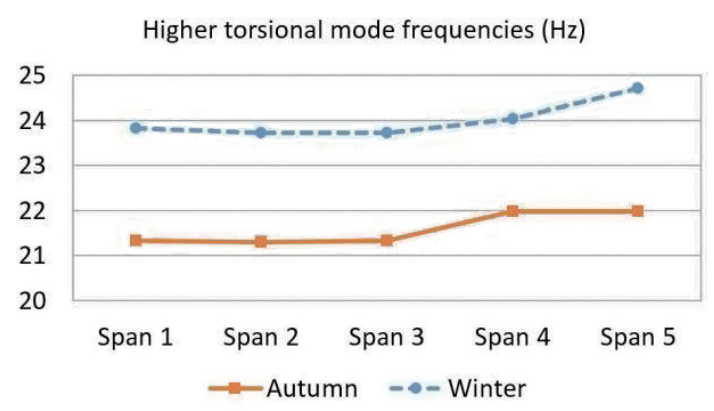

(a)

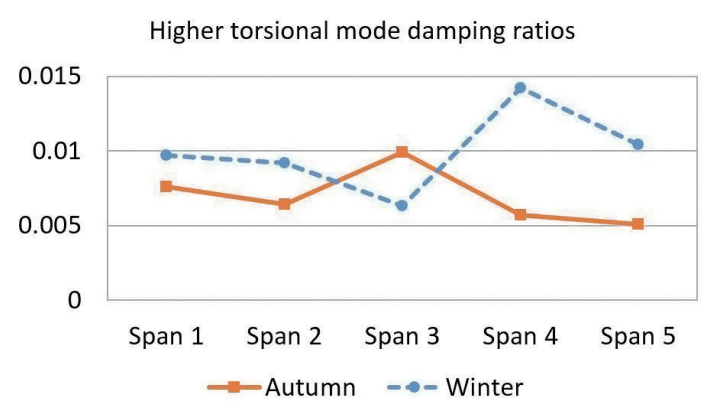

(b)

Fig. 13. (Color online) Third-mode parameters of five spans in autumn and winter. (a) Frequency and (b) damping ratio.

of every span in any assigned mode were basically the same. As a result, the two curves in Figs. 11(a)-13(a) were mainly parallel. It could be empirically hypothesized that this seasonal increase in the natural frequency could have three possible causes. Firstly, the decrease in temperature contributed to the increase in Young's modulus of concrete. Secondly, the emergence of frost inside the supports altered the boundary conditions of the girders. Finally, the frozen ballast and frost on the deck increased the stiffness of the bridge. Subsequently, a series of investigations were conducted after the analysis. 
To begin with, the air temperatures on autumn and winter experiment days are shown in Fig. 14. The average daily air temperature in the autumn experiment was around $8{ }^{\circ} \mathrm{C}$, whereas that in the winter experiment was around $0{ }^{\circ} \mathrm{C}$. The air temperature difference between the two experiment days was about $8{ }^{\circ} \mathrm{C}$. From previous studies, we know that such a small temperature gap cannot result in large natural frequency differences between the two experiments. Consequently, the temperature decrease in winter was not the main reason for such large seasonal natural frequency increases.

Furthermore, the conditions of supports were investigated one by one, as shown in Fig. 15. Even though there was a small amount of snow around the supports, the condition of all the supports was unchanged. There was no frost inside the supports. Thus, the boundary condition variation of girders was not the cause of the natural frequency increase in the experiments.

The frozen ballast and the frost on the walkway are shown in Figs. 16 and 17, respectively. The space between ballasts was filled with ice. The existence of ice markedly changed the interaction mechanism of the ballast. The ballast was transformed into another new composite material that is similar to concrete. In this case, the ballast performed as an aggregate and the ice inside the ballast could be seen as a filler, just like cement. Therefore, the mechanical property of ballast

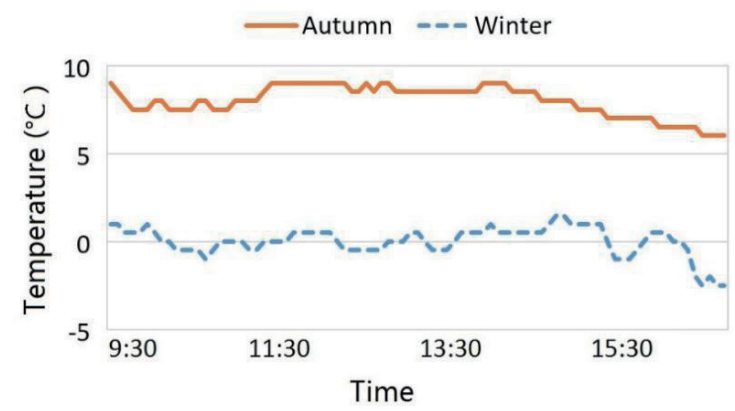

Fig. 14. (Color online) Air temperature on autumn and winter experiment days.

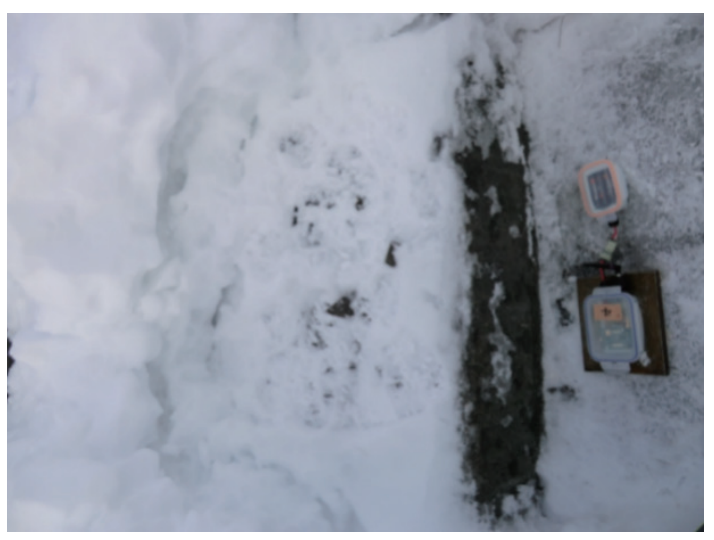

Fig. 16. (Color online) Frozen ballast.

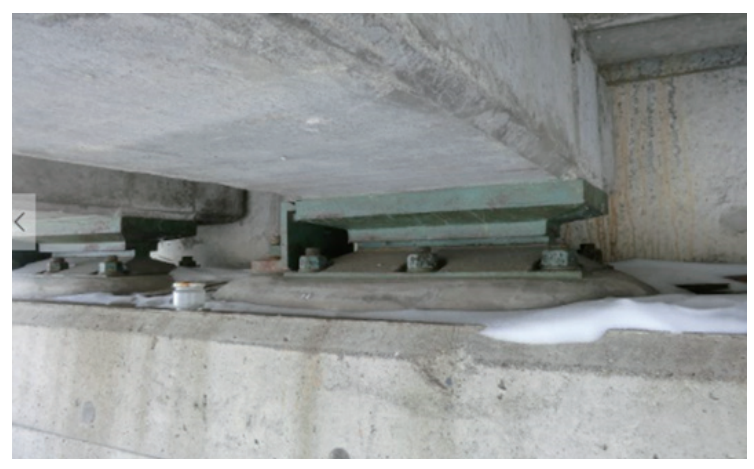

Fig. 15. (Color online) Investigation of support condition .

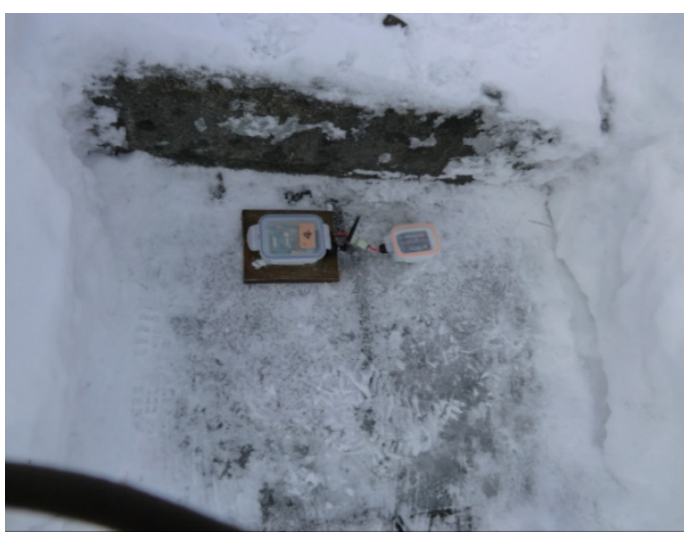

Fig. 17. (Color online) Frost on the walkway. 
considerably changed. Meanwhile, the depth of frost on the walkway was also measured. The result showed that the average depth of frost on the walkway was approximately $3 \mathrm{~cm}$. The frozen ballast and the frost on the walkway were closely attached to the girders. Under these circumstances, the stiffness of the girders was increased significantly. Thus, the frozen ballast and the frost on the walkway were found to be reasonable explanations for the phenomenon of the seasonal natural frequency increase. In addition, the effects of frozen ballast and a frozen deck on the natural frequency increase are so strong that they could easily offset the effect of snow load on the natural frequency decrease.

\subsection{Damping ratios}

For damping ratios, the results were more difficult to comprehend, as shown in Figs. 11(b)13(b). The damping ratio of every span in any assigned mode was significantly different between autumn and winter. In about half of the tests, damping ratios were higher in the autumn tests than in the winter tests, and in the other tests, damping ratios were lower in the autumn tests than in the winter tests. Furthermore, from the relationship between the two curves in any damping ratio figure [Figs. 11(b)-13(b)], the two damping ratio curves were not as parallel as the two frequency curves in the frequency figures [Figs. 11(a)-13(a)], and the relationship between the two curves did not have any clear regularity. Three possibilities could explain this seasonal damping ratio variation. First of all, with the emergence of frost, the girders became much stiffer, so that the damping ratios should increase in accordance with the viscous damping theory. Secondly, owing to the existence of frost and snow, the surface distribution load on the deck was increased. The increasing surface mass would lead to the decreasing damping ratios. Thirdly, about $50 \mathrm{~cm}$ of snow also acted as a damper. When the bridge was vibrating, the snow could absorb part of the energy. This may also contribute to the increasing damping ratios. Therefore, positive and negative correlation factors of damping ratios existed simultaneously in winter. However, owning to the uncertainties of frost and snow, the effects of the above three factors on the damping ratios varied in different locations and situations. This could be one acceptable explanation for the damping ratio variation.

\section{Conclusions}

A fundamental application of the wireless acceleration sensor network system was carried out by conducting two bridge vibration experiments in autumn and winter. Seasonal effects on the dynamic characteristics of a multispan ballasted PC railway bridge were investigated as a basic study of SHM technology.

By comparison between autumn and winter experiment results, two points were confirmed. As the first point, natural frequencies were increased significantly in winter owning to the frozen ballast and the frost on the walkway. The existence of frozen ballast and frost on the walkway could considerably increase the stiffness of girders, and the effect of this stiffness increase on the natural frequencies could not be offset by the snow distribution load. As the second point, seasonal effects on damping ratios were more difficult to comprehend. Which season has the higher damping ratios was unclear. The increasing stiffness of girders, increasing distribution load, and the existence of snow could affect the damping ratios simultaneously, and the weights of the three factors still must be studied further.

By conducting the two experiments in this research, the convenience and efficiency of employing a wireless acceleration sensor network system instead of the traditional wired acceleration sensor 
system was shown without any doubt. The wireless acceleration sensor network system definitely makes the vibration measurement of civil engineering structures more flexible and efficient, and it should be widely promoted in the civil engineering field.

\section{Acknowledgements}

This research was supported by JSPS Grant-in-Aid for Scientific Research \#(C) Grant Number $15 \mathrm{~K} 06176$.

\section{References}

1 J. A. Rice, K. Mechitov, S. H. Sim, T. Nagayama, S. Jang, R. Kim, B. F. Spencer, Jr., G. Agha, and Y. Fujino: Smart Struct. Syst. 6 (2010) 423.

2 Y. Miyamori, T. Kadota, Y. Zhang, and S. Mikami: Proc. Int. Conf. Smart Infrastructure and Construction (ISCIC), eds. R. J. Mair, K. Soga, Y. Jin, A. K. Parlikad, and J. M. Schooling (Robinson College, Cambridge, June 2016.) pp. 167-172.

3 S. Jang, H. Jo, S. Cho, K. Mechitov, J. A. Rice, S. H. Sim, H. J. Jung, C. B. Yun, B. F. Spencer, Jr., and G. Agha: Smart Struct. Syst. 196 (2010) 439.

4 C. Boller, F. Chang, and Y. Fujino: Encyclopedia of Structural Health Monitoring, eds. C. Boller, F. Chang, and Y. Fujino (Wiley, West Sussex, 2009) Vol. 1.

5 D. M. Siringoringo, Y. Fujino, and T. Nagayama: J. Eng. Mech. 139 (2013) 691.

6 M. Dilena and A. Morassi: Mech. Syst. Signal Process. 25 (2011) 1485.

7 I. Gonzales, M. Ülker-Kaustell, and R. Karoumi: Eng. Struct. 57 (2013) 63.

8 Y. Xia, B. Chen, S. Weng, Y. Q. Ni, and Y. L. Xu: J. Civil Struct. Health Monit. 2 (2012) 29.

9 T. Nagayama and B. F. Spencer: Structural Health Monitoring using Smart Sensors, NSEL Report 1, https:// www.ideals.illinois.edu/ (accessed 2007).

10 ISHMP: SHM-H Board High-Sensitivity Accelerometer Sensor Board Datasheet and User's Guide, http:// shm.cs.uiuc.edu/ (accessed 2009).

11 Crossbow: Imote2 High-Performance Wireless Sensor Network Node, http://www.xbow.com (accessed 2007).

\section{About the Authors}

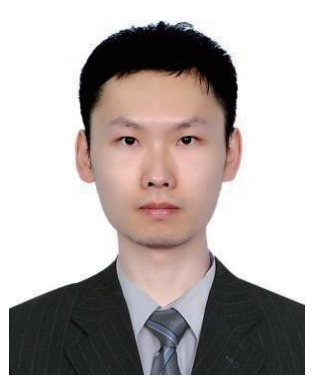

Youqi Zhang received his M.S. degree from Northeast Dianli University, China, in June 2016. In October 2016, he started his Ph.D. course at Kitami Institute of Technology, Japan. His research interest is in bridge health monitoring.

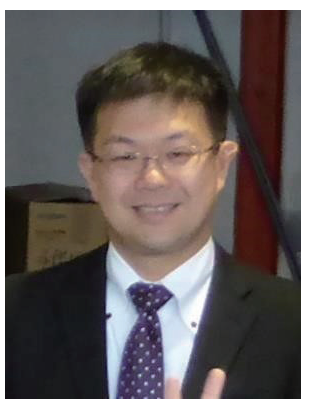

Yasunori Miyamori received his Ph.D. degree from Hokkaido University, Japan. He is an associate professor in the Department of Civil and Environmental Engineering, Kitami Institute of Technology, Japan. His main area of interest is bridge engineering and dynamic responses of structures. 


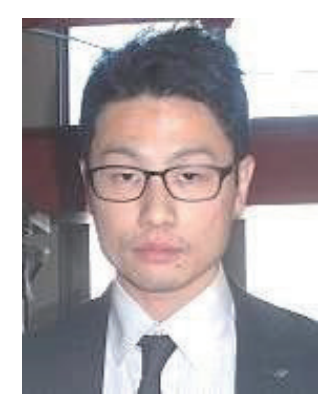

Takanori Kadota received his M.S. degree from Kitami Institute of Technology, Japan, in March, 2006. In April, 2006, he joined the Oriental Consultants Co. Ltd., Tokyo, Japan, as a civil engineer. He also started his Ph.D. course at Kitami Institute of Technology, Japan, in April, 2014. His research interest is in bridge health monitoring.

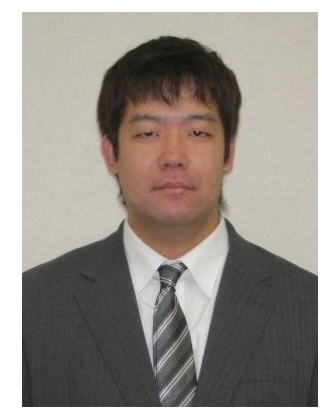

Takehiko Saito received his M.S. and Ph.D. degrees from Tokushima University, Japan, in 2008 and 2012, respectively. Since 2012, he has been an assistant professor at Kitami Institute of Technology, Japan. His research interests are in bridge health monitoring and tsunami risk management. 